\title{
SUPERIORITY OF FLOURESCENT IN SITU HYBRIDIZATION OVER IMMUNOHISTOCHEMISTRY IN DETECTION OF HER2 GENE IN CARCINOMA OF THE URINARY BLADDER ASSOCIATED WITH AND WITHOUT SCHISTOSOMIASIS
}

\author{
By \\ OLFAT HAMMAM ${ }^{* 1}$, MOHAMED WISHAHI ${ }^{2}$, ALI HINDAWI ${ }^{3}$, MAHA MOSAAD $^{3}$, \\ MAHA AKL ${ }^{1}$, HEBA KHALIL ${ }^{1}$, HOSSAM AL GANZOURY ${ }^{3}$, \\ MOHAMED BADAWY ${ }^{3}$ AND KHALED ELESAILY ${ }^{3}$ \\ Departments of Pathology ${ }^{1}$ and Urology ${ }^{2}$, Theodor Bilharz Research Institute, \\ Imbaba, Giza, and Department of Pathology ${ }^{3}$, Faculty of Medicine, \\ Cairo University, Cairo, Egypt \\ *Correspondence (E-mail: totoali1@hotmail.com),(moh.weshahy@gmail.com)
}

\begin{abstract}
HER2 is an oncogene encoding a type 1 tyrosine kinase growth factor receptor and the role of HER2 in the development of numerous types of human cancer is still understood and correlates with clinical outcome, poor prognosis, it is a predictor factor for poor response to chemotherapy. HER2 overexpression is associated with reduced disease free and overall survival. Patients who have HER2 negative expression have a poor prognosis. The aim of the present study is to explore the accuracy of detection of expression of HER2 protein by two different techniques of immunohistochemistry (IHC) and gene amplification by fluorescent in situ hybridization (FISH). The two techniques were applied to sixty two patients that included different cell types of carcinoma of the bladder, benign bilharzial lesions and control. Characteristics of the 62 patients are: 10 chronic cystitis, 19 squamous cell carcinoma (SCC) with schistosomiasis, 33 urothelial carcinoma (UC) schistosomal and non-schistosomal, ten healthy individuals without schistosomiasis served as controls. Gene amplification of HER2 was done using FISH and protein expression of HER2 by IHC. The study was applied on archival data of formalin-fixed paraffin embedded tissues and patient clinical data and follow up for 5 years. Overexpression of HER2 protein was found in 30/52 (57.7\%). Fourteen cases had score of $2+$, and sixteen cases had score of $3+$. Using FISH technique it showed more accurate detection of HER2 gene as those fourteen cases who had score of $2+$ had been found to be 5 out of 14 were positive for gene over expression, the other sixteen who had score of $3+$ all were positive for gene amplification. HER2 protein and gene was found to be significantly overexpressed in carcinoma of the bladder in both cell types SCC and UC with or without schistosomiasis compared to the benign lesions and control groups $(\mathrm{P}<0.01)$ by both techniques. There is significant increase in expression of HER2 protein and gene in SCC compared to UC $(\mathrm{P}<0.01)$. In UC overexpression of HER2 protein and gene was evident in all stages Ta, T1, T2-4. HER2 protein and gene overexpressed in different grades of UC. In SCC HER2 protein and gene had overexpression in different stages and grades.
\end{abstract}

Keywords: Carcinoma of the bladder, HER2 gene, HER2 protein, immunohistochemistry, FISH, Schistosomiasis.

\section{Introduction}

Carcinoma of the bladder in Egypt has the highest recorded incidence rate of bladder cancer in the world, and the incidence of 37.1 per 100,000 males is almost two times higher than in Western communities and first among Northern African and Arabian African countries (Parkin et al, 2005). At the
National Cancer Institute (NCI), it constitutes $30.3 \%$ of all cancers, $40.6 \%$ of male cancers, and $14.3 \%$ of female cancers (ElBolkainy et al, 2000).

Patients with carcinoma of the bladder have a high rate of survival (90\%) if the disease is diagnosed at an early stage. However, the presence of even superficial invasion into the muscularis propria results in a dra- 
matic fall in the 5-year survival rate to < $50 \%$. Patients with metastatic bladder carcinoma are treated with systemic chemotherapy, but their disease remains a virulent disorder for which there is no cure. The standard treatment for patients with muscleinvasive bladder carcinoma is a radical cystectomy. Approximately $50 \%$ of patients will develop recurrences and die of their disease. Attempts to reduce recurrence rate by translating chemotherapy advances in metastatic disease into studies of neoadjuvant or adjuvant chemotherapy for patients with high-risk, organ confined tumors. Neoadjuvant cisplatin, methotrexate, and vinblastine (CMV) chemotherapy improves outcome as first line adjunctive treatment for invasive bladder cancer. Two large randomized trials (by the Medical Research Council/European Organization for Research and Treatment of Cancer and Southwest Oncology Group) have confirmed a statistically significant and clinically relevant survival benefit, and neoadjuvant chemotherapy followed by definitive local therapy should be viewed as state of the art, as compared with cystectomy or radiotherapy alone, for deeply invasive bladder cancer (Griffiths et al, 2011).

HER2 oncoprotein, also known as (NEU, EGFR2, or ERBB2) is one of the members of the Epidermal Growth Factor Receptor (EGFR) family, which includes EGFR or (ERBB1), EGFR3 or (HER3/ ERBB3) and EGFR4 or (HER4/ERBB4) is known to contribute to physiological mechanisms of cell proliferation by intrinsic tyrosine kinase activity. Overexpression has been shown for several tumors and is known to influence malignant cell proliferation, metastasis and angiogenesis (Wülfing et al, 2005).

Overexpression of HER2 has been associated with some different types of human cancers. HER2 (c-erb B2) is an oncogene encoding a type 1 tyrosine kinase growth factor receptor (Ramzi et al., 2000). HER2 overexpression and/or amplification have been detected in 10\%-34\% of invasive breast cancers (Kaptain et al, 2001), gastric carcinoma (Gravalos and Jimeno 2008), colonic carcinoma (Schuell et al, 2006) and bladder cancer (Eltze et al, 2005). The incidence of overexpression of HER2 in bladder cancer is one of the highest among all human malignancies, ranging from $9 \%$ to $34 \%$ of cancers tested (Sato et al, 1992).

Trastuzumab (Herceptin) is a monoclonal antibody which specifically targets HER2 protein by directly binding the extracellular domain of the receptor. Trastuzumab enhances survival rates in both primary and metastatic HER2 positive breast cancer patients (Smith et al, 2007). The efficacy of Trastuzumab in breast cancer patients has led to investigate its antitumor activity in patients with HER2 positive cancers, including bladder cancers.

Studies of bladder carcinoma that have analyzed gene amplification and/or increased protein expression of HER2 by a variety of methods have shown mixed results. Whereas several studies have reported its association with higher disease stage, increased tumor progression, and increased metastasis (Korkolopoulou et al, 1997).

Studies in bladder cancer have revealed a discrepancy between gene amplification and protein expression of $\mathrm{C}$-erb-B2, and their value as a prognostic marker remains controversial (Krüger et al, 2002). The majority of this controversy appears to have been caused by technical variables associated with the different reagents and/or methodologies used in testing for the presence of the C-erb-B2 alteration specially the noted discrepancy between gene amplification and overexpression (Underwood et al, 1995).

The aim of the present study is to explore the accuracy of detection of expression of HER2 protein by two different techniques of immunohistochemistry (IHC) and gene amplification by fluorescent in situ hybridization (FISH).

\section{Patients, Materials and Methods}

The enrolled 62 patients were admitted to the Urology Department at the Theodor Bil- 
harz Research Institute (TBRI) Hospital with bladder lesions. Forty one (41/62) of them were associated with schistosomiasis. Schistosomal infestation was diagnosed by identifying the schistosoma ova in urine and tissue samples or detecting schistosomal antibodies in serum using ELISA technique.

The patients consisted of 39 males and 23 females (aged from 25 to 70 years; mean age $47.5 \pm 3.2$ years). Ten patients subjected to prostatectomy served as normal controls after obtaining their consent. Bladder biopsies were taken during prostatectomy from the trigon area. Tumor specimens were obtained by cystoscopy (transurethral resection biopsies [TUR]). Only biopsies containing muscle tissue were included, so that muscle invasion by the tumor could be assessed. The study protocol was approved by the institutional committee for the protection of human subjects and conformed to the guidelines of the 1975 Declaration of Helsinki. Patients were subjected to full clinical examination, routine laboratory investigations, complete urine analysis, abdominal and pelvic ultrasonography, general and abdominal examination, digital rectal examination (DRE), bimanual examination under anesthesia, plain X-ray of the urinary tract, intravenous urography (IVU), cystoscopy and TUR biopsies were taken from apparent growths.

Histopathological study: Tissues were fixed in $10 \%$ buffered formalin, paraffinembedded and processed routinely. Hematoxylin and Eosin stains were used to evaluate all bladder lesions and to assess carcinoma grade and stage (Eble et al, 2004). Samples were classified into six groups: Group: control (10 cases); G1: chronic nonspecific cystitis (4 cases); G2: chronic schistosomal cystitis (6 cases); G3: nonschistosomal-associated urothelial carcinoma (17 cases); G4: schistosomal-associated urothelial carcinoma (16 cases); G5: schistosomal-associated SCC (19 cases).

Immunohistochemistry of HER2 antibody: Bladder sections $(4 \mu)$ were collected from formalin-fixed, paraffin blocks on mi- croscopic slides coated with 3-amino propyl triethoxy silane (Sigma). The used the standard streptavidin-biotin peroxidase complex method (APC) method, according to Hsu et al. (1981). Following deparaffinization and rehydration. Endogenous peroxidase activity was blocked using $3 \%$ solution of hydrogen peroxide in methanol for 30 minutes at room temperature then antigen retrieval was performed by microwaving in $10 \mathrm{mM}$ citrate buffer, $\mathrm{pH} 6.0$ for 15 minutes. Non-specific antibody binding was prevented by pre-incubation with $100 \mathrm{~mL}$ blocking serum for $30 \mathrm{~min}$ at room temperature. Sections were incubated overnight with the primary antibodies: HER2 monoclonal antibody (Dako, Glosturp, Denmark) at the optimal working dilution of 1:100. After thorough washing in buffer, we used substrate chromogen mixture (A biotinylated secondary anti-immunoglobulin (IgG) LSAB ${ }^{\circledR}$ System (k0679), a preformed Streptavidin biotinylated horseradish peroxidase complex and the chromogen used were 3-3' diaminobenzidine tetrahydro-chloride (D.A.B.) (DAKO, Denmark) and sections were counterstained with Mayer's hematoxylin before mounting. Positive control was done using breast cancer. Negative control slides included a blank control and omission of primary antibody. Positive and negative controls were stained in the same settings (battery) of stain to standardize our technique.

Interpretations of HER2 expression by immunohistochemistry: Negative: (Score 0) no staining is observed or membrane staining is observed in less than $10 \%$ of tumor cells. (Score 1+) a faint/barely perceptible membrane staining is detected in more than $10 \%$ of tumor cells. The cells are only stained in part of their membrane. Weakly positive (equivocal) :( Score $2+$ ) a weak to moderate complete membrane staining is observed in more than $10 \%$ of tumor cells. Strong positive: (Score 3+) a strong complete cell membrane staining is observed in in more than $10 \%$ of the tumor cells (Tryls et al, 2005). 
Gene expression of HER2 by fluorescence in situ hybridization: In order to test HER2 gene amplification in bladder carcinoma associated with or without schistosomiasis, a FISH analysis was performed on a representative proportion of the tumors using the Path Vysion kit. All samples presenting +ve HER2 protein expression were evaluated using labeled probes for both Fluorophore Vysis LSI HER2 17q11.2-12 Spectrum Orange Vysis and CEP 17 17p11.1-q11.1 Alpha Satellite DNA Spectrum Green HER2 specific DNA sequences (17q11.2-q12 region) and the centromere of chromosome 17, CEP17 (alpha satellite DNA located at locus 17p11.1q11.1), were used (HER2, FISH, Abbott Molecular Diagnostics, INC, USA).

Paraffin was removed from $4 \mu$ tissue sections by washing the slides in xylene for 10 min, then in $100 \%$ alcohol for 5 min twice, then air dried. Immerse slides in pretreatment solution at $80^{\circ} \mathrm{c}$ for 15 minutes, and then tissue sections were digested with protease solution by immersion slides in solution at $37^{\circ} \mathrm{c}$ for 5 minutes. Air dry slides for 2-5 minutes. Tissue sections were post fixed in $10 \%$ neutral buffered formalin at room temperature for $10 \mathrm{~min}$ before dehydration in ascending grades of alcohol and air drying, Tissue sections were denatured in the denaturation solution at $72^{\circ} \mathrm{C}$ for $5 \mathrm{~min}$. Then in ascending grades of alcohol $70 \%$, $95 \%, 100 \%$ alcohol for $1 \mathrm{~min}$ each, air dry slides for 2-5 minutes. Probes for the pericentromeric region of chromosome 17 (Spectrum Green ${ }^{\mathrm{TM}}$ ) and the locus specific probe for HER2 (Spectrum Orange ${ }^{\mathrm{TM}}$ ) were used. For each section, $1 \mu \mathrm{l}$ of each probe was added to $7 \mu \mathrm{l}$ hybridization mix (50\% formamide, $2 \times \mathrm{SSC}, 10 \%$ dextran sulphate) and $1 \mu \mathrm{l}$ deionized water and denatured in a water bath at $72^{\circ} \mathrm{C}$ for $5 \mathrm{~min}$ and then hybridized overnight at $37^{\circ} \mathrm{C}$. Posthybridisation washes were done by immersing slides in pre-warmed $2 \mathrm{X} \mathrm{SSC} / 0.3 \% \mathrm{NP}-40$ at $73.1^{\circ} \mathrm{C}$, for $2 \mathrm{~min}$. Air dry slides in darkness. Slides were mounted in $10 \mu \mathrm{l}$ di- aminido phenyl indol (DAPI)/ antifad. Control sections of normal bladder and HER2/ neugene amplified breast tumors were included in each run.

Fluorescence in-situ hybridization of HER2 gene scoring: Serially sectioned haemtoxylin and eosin stained tissue sections were first examined to localize areas of UC and SCC. FISH sections were then scanned at $\times 400$ magnifications to localize the areas of interest. Slides were viewed with a Florescent Olympus microscope $\mathrm{x} 51$, a triple band pass filter block spanning the excitation and emission wavelengths of the SpectrumO range $^{\mathrm{TM}}$ and SpectrumGreen ${ }^{\mathrm{TM}}$ and DAPI was used in the analysis of the hybridization, filter and images were captured with a charge coupled device camera, filtered and processed with Applied Imaging System (Cytovision software 2.3). In total, three areas were identified and in each area $60 \mathrm{nu}$ clei were assessed. Chromosome 17 copy numbers and HER 2 copy number were assessed for each of the 60 nuclei at $\times 1000$ magnification. A ratio of chromosome 17 copy number over HER2 copy number was obtained in the 60 nuclei. Control sections of normal bladder and HER2 gene amplified breast tumors were included in each run. HER2 was classified as: amplified when they showed a HER2 centromere 17 ratio>2.2 and as non-amplified when the HER 2 centromere 17 ratio was $<2$. Polysomy cases in which more than one chromosome within the nucleus (More than 2 green signals) should considered as negative cases (Bartlett et al, 2001) based on the value used in breast cancer diagnostics.

Statistical analysis: Data available for statistical evaluation was performed with Statistical Package for the Social Sciences SPSS (version 17.0, IBM, Chicago, IL, USA) for windows software. Initially, a descriptive analysis of all collected variables was performed. The correlation between expression of HER 2 and tumor grade and stage were assessed with Fisher's exact and chi- 
square tests. All differences were deemed significant at level of $p<0.05$.

\section{Results}

Immunohistochemical studies of HER2 protein by IHC: No expression of HER2 protein in control and chronic non-specific $\&$ schistosomal cystitis groups. Twenty two out of $52(42.4 \%)$ of malignant cases were negative, $14 / 52$ are equivocal $(26.9 \%)$ and $16 / 52(30.7 \%)$ are positive score 3+. Malignant cases showed statistically significance increase in positive cases comparing to control and cystitis cases at $\mathrm{P}<0.01$.

In SCC cases is positive $(36.9 \%)$ and in UC 9/33 cases are positive (27.3\%), Cases of SCC showing statistically significant increase in percentage of positive HER2 protein immunoexpression comparing to $\mathrm{UC}$ $(\mathrm{P}<0.01)$.

Non schistosomal UC cases showing 4/17 cases are positive for HER2 immunoexpression $(23.5 \%)$ and in schistosomal UC 5/ 16 cases are positive $(31.3 \%)$. Schistosomal associated UC, non schistosomal associated UC, and SCC showed statistically significance increase comparing to control, schistosomal and non schistosomal cystitis at ( $\mathrm{p}<0.01, \mathrm{p}<0.01$ and $\mathrm{p}<0.01$ respectively). Cases of SCC showing statistically high significance compared to non schistosomal associated UC $(\mathrm{p}<0.01) 9$ (Tab.1\&Fig.1[A$\mathrm{F}]$ ).

On stratifying urothelial carcinoma according to grade, cases of UC of low grade malignancy showed no positive cases for HER2 immunoexpression and high grade malignancy showing positive HER2 protein immunoexpression in 9/24 cases (37.5\%). Urothelial cell carcinoma cases of high grade malignancy showing statistically significant increase in number of positive HER2 immunoexpression compared to low grade cases $(\mathrm{P}<0.01)$. No significance in HER2 protein positivity between low and high grade malignancy in SCC cases.

On stratifying urothelial carcinoma according to invasion of muscle, in Ta no positive cases $0 / 13$, in $\mathrm{T} 13 / 7$ cases were posi- tive $(42.9 \%)$ and in T2\& T3 6/13 cases were positive $(46 \%)$. Cases with stage $\mathrm{T} 1$ and T2\&3 showed statistically significance increase percentage of positive HER 2 protein immunoexpression compared to Ta cases $(\mathrm{p}<0.01, \mathrm{p}<0.01$ respectively). Squamous cell carcinoma showed no significant difference in HER2 immunoexpression in different stages (Tab. 2; Fig.1, A-F]).

HER2 gene expression using FISH: All control and cystitis with or without schistosomiasis cases were negative. Twenty seven cases out of 52 cases of malignancy $(51.9 \%)$ are negative, 4 cases $(7.7 \%)$ showing polysomy, 21 cases are positive $(40.4 \%)$, for HER2 gene amplification. Malignant cases showing statistically significant increase in percentage of positivity in malignant cases compared to control and cystitis cases $(\mathrm{P}<0.01, \mathrm{P}<0.01)$ respectively.

In urothelial carcinoma 11/33 were positive $(33.4 \%)$ and in SCC 10/19 were positive (52.6\%). SCC patients showing statistically significance increase in percentage of positive HER2 gene amplification comparing to UC $(\mathrm{p}<0.01)$. In non schistosomal UC 6 were positive $(35.3 \%)$ and in schistosomal UC 5 were positive $(31.25 \%)$.

According to the classification of UC cases of different grades, all low grades were negative for HER gene amplification, but 11 patients with high grade were positive $(11 / 24,45.9 \%)$, UC patients of high grade malignancy showing statistically significant increase in number of positive HER2 gene expression compared to low grade cases $(\mathrm{P}<0.01)$. No significance in HER2 gene expression between low and high grade malignancy in SCC (Tab.1; Fig. 2, A-D).

According to the classification of UC cases of different stages $1 \mathrm{Ta}(1 / 137.7 \%), 3 \mathrm{~T} 1$ patients $(3 / 7,42.9 \%)$, and 7 T2\&T3 patients were positive $(7 / 13,53,8 \%)$. Cases with stage T1 showing statistically significance increase percentage of HER2 gene expression compared to Ta cases $(\mathrm{p}<0.01)$, patients with stage T2\&T3 showing statistically sig- 
nificant increase in percentage of HER2 gene expression compared to $\mathrm{Ta}$ and $\mathrm{T} 1$ $(\mathrm{p}<0.01, \mathrm{p}<0.05)$. Cases of T2\&T3 showed statistically significant increase in number of positive HER2 gene expression compared to T1 (P<0.01) (Tab.2; Fig. 2, A-D).

In malignant studied cases (52 cases), 22 cases were negative for HER2 protein immunoexpression, 14 cases had score of $2+$ (equivocal) and sixteen cases had score of $3+$ (positive). Using FISH technique it showed more accurate detection of HER2 gene as those fourteen cases who had score of $2+$ had been found to be 5 out of 14 were positive for gene over expression, the other sixteen who had score of $3+$ all were positive for gene amplification.

\section{Discussion}

Bladder carcinoma is one of the commonest malignancies in Egypt and including bilharzial and non bilharzial carcinoma. Approximately $93 \%$ of these tumors are derived from the epithelial lining and are termed urothelial carcinoma (Droller. 1998). Similar to other epithelial malignancies, patients with carcinoma of the bladder have a high rate of survival (90\%) if the disease is diagnosed at an early stage (Felix et al, 2008). However, the presence of even superficial invasion into the muscularis propria results in a dramatic fall in the 5-year survival rate to $<50 \%$ (Borden et al, 2004). $\mathrm{Pa}$ tients with metastatic bladder carcinoma are treated with systemic chemotherapy, but their disease remains a virulent disorder for which there is no cure.

HER-2 gene received attention in the early 1990s, with several studies aimed at defining its role in bladder TCC and its capacity as a prognostic indicator. The prognostic value of HER2 in bladder carcinoma has not been established; however, the success of trastuzumab therapy in patients with breast carcinoma has stimulated interest in exploring the potential. The incidence of overexpression of HER 2 in bladder cancer is one of the highest among all human malignancies, ranging from $9 \%$ to $34 \%$ of cancers tested
(Sato et al, 1992). Its prognostic value and correlation with tumor stage and grade has been variably reported.

HER2 overexpression could be evaluated by IHC, fluorescence in situ hybridization (FISH), and serum analysis. The best method to detect HER2 overexpression in urothelial cancer is not known. Because the greatest clinical benefit is observed in patients with the highest levels of HER2 expression, trastuzumab trials in breast cancer often require eligible patients to have either $3+$ overexpression by IHC or $2+$ overexpression by IHC with positive FISH results. However, initial studies permitted patients with $2+$ or $3+$ overexpression by IHC (Atias, 2007).

Studies in bladder cancer have revealed a discrepancy between gene amplification and protein expression of $\mathrm{C}$-erb-B2, and their value as a prognostic marker remains controversial (Krüger et al, 2002). The majority of this controversy appears to have been caused by technical variables associated with the different reagents and/or methodologies used in testing for the presence of the C-erb-B2 alteration special the noted discrepancy between gene amplification and overexpression (Underwood et al, 1995).

The evidence linking schistosomiasis to urinary bladder cancer is strong, and the International Agency for Research on Cancer has classified $S$. haematobium infection as carcinogenic (IARC Working Group, 1994). Urinary schistosome infections typically occur in less developed countries and are endemic in countries such as Egypt, Iraq, and Sudan; these countries also have high rates of bladder cancer (Mostafa et al, 1999). Bladder cancers diagnosed in schistosomiasis areas are usually high-grade squamous cell carcinomas (Koraitim, 1995). However, it appears that the histopathology of bladder cancer in areas where schistosomiasis is endemic may be changing. In a recent study of schistosomiasis- associated bladder cancer conducted in Egypt, the proportion of transi- 
tional cell carcinoma increased over time ( $31 \%$ in 1960 s vs. $42 \%$ in late 1980 s).

HER2 (c-erb-B2) is a proto-oncogene located on chromosome $17 \mathrm{q} 21$. It is a transmembrane protein characterized by an extracellular domain that interacts with various growth factors a transmembrane with tyrosine kinase activity. It is expressed in various human cancers, including lung squamous cell carcinoma and stomach and breast adenocarcinoma. In urothelial carcinomas it is some- times, but not always, associated with aggressive behavior (Nakopoulou et al, 1998).

In The present study, all control and cystitis cases were negative for HER2 protein immunoexpression (Score 0 or Score 1+). These agreed with the study of El Baz et al. (2000) who found in their study using immunohistochemistry that c-erbB-2 oncoproteins were not expressed neither in morphologically normal nor in the hyperplastic epithelium.

In the current study, using immunohistochemistry to detect HER2, we found, $21.2 \%$ of malignant cases are positive score $3+$ and malignant cases showing statistically high significance increase in number of positive cases for HER2 protein immunoexpression comparing to control and cystitis cases $(\mathrm{P}<0.0)$. This agreed with Al-Tereihi et al. (2011) who found HER2 overexpression positive in $41.6 \%$ of urinary bladder carcinoma cases, while there was no expression in benign bladder tissue.

In the present study, cases were found stained with HER2 immunohistochemistry diagnosed as UC showed $27.4 \%$ positive cases, while in SCC cases $10.5 \%$ are positive. Cases of UC showed statistically significant increase in percentage of positive HER2 protein immunoexpression comparing to SCC $(\mathrm{P}<0.01)$. These agreed with AbdElmoneim et al. (2011) who found over expression of HER2 protein in $47.8 \%$ of UC and in $46.3 \%$ of SCC and El Gehani et al. (2012) who found in their study that HER2 over-expression was observed in 23/39 tu- mors (59\%) and Hansel et al. (2008) in which HER 2 protein ,overexpression in $36 \%$ UC.

The use FISH technique to detect gene overexpression of HER 2 and all cystitis cases were negative, 15 cases out of 52 cases of malignancy are positive $(28.9 \%)$ for HER2 gene amplification. The statistical significant difference was in positivity of HER2 protein by immunohistochemistry between cystitis (schistosomal and non schistosomal) and malignant cases. This finding agreed with Wester et al. (2002) and Nadoushan et al. (2007).

It is now a prevailing hypothesis that cancer cell behavior is determined by a single genetic event or more likely cumulative genetic events resulting in molecular changes affecting cancer cell physiology and its interaction with the host organism. It is now possible to study these genetic abnormalities, alterations in oncogene and tumorsuppressor genes, and changes in cellular molecules using a panel of potential diagnostic and prognostic markers (Jung and Messing, 2002).

In the present study, the HER2 overexpression by IHC was found in $16.7 \%$ of our cases of SCC associated with schistosomiasis, while in the study of Badr et al. (2004) they found in his study that $27 \%$ of squamous cell carcinoma associated with schistosomiasis cases showing abnormal HER2 immunoexpression, this discrepancy in the percentage of positive cases may be due to the difference in the scoring system used.

In study of Aly et al. (2004) on squamous cell carcinoma associated with schistosomiasis in which divide the expression of HER2 gene as normal and abnormal, he found that 9 out of 21 cases of squamous cell carcinoma associated with schistosomiasis showing abnormal HER2 gene in $42.8 \%$. In the present study, cases of squamous cell carcinoma were associated with schistosomiasis showing abnormal HER2 gene using FISH technique in $42.7 \%$ (including $8.3 \%$ polysomy and $34.4 \%$ true positive HER 2 gene 
amplification) that agreed with the result of Aly et al. (2004).

In the current study HER2 expression was detected in $36.9 .5 \%$ of the SCC samples, all were schistosomiasis associated, but it was not significantly related to grade. This observation agreed with the results of El Gehani et al. (2012) and Badr et al. (2004) who reported no link in the protein expression of c-erbB-2 and tumor grade in SCC cases.

In the studies of Al-Tereihi et al. (2011) and Charafi et al. (2013) there was a gradual increase in the frequency of HER2 overexpression by IHC technique in parallel with the increase in the grade in transitional cell carcinoma cases (in grade I there was 35\% HER2 overexpression, in grade II $38.8 \%$ and in grade III 50\%) with significant difference among the three degrees of differentiation $(\mathrm{p}<0.05)$. This fact was proved by other studies (Khan, 1998). There is a significant difference between superficial low grade tumor (Ta) and the invasive high grade tumor (T2 \&T3 and T4) $(\mathrm{P}<0.05)$ but there is no significant differences between T2 \&T3 and T4 themselves, this also agreed with Badr el al. (2004) but disagreed with El Gehani et al. (2012) in which a significant correlation between HER2 expression and the tumor stage $(\mathrm{p}<0.011)$.

Numerical aberrations of some chromosomes identified by chromogenic in situ hybridization (CISH) and fluorescence in situ hybridization (FISH) seem to be involved in progression to detrusor-muscle invasion and have been associated with an aggressive tumor behavior or recurrence of disease (Trkova et al, 2006), in particular, aberrations affecting chromosome 17 as polysomy (Latif et al, 2003; 2004). It was found that polysomy of chromosome 17 is involved in the progression to detrusor-muscle invasion and has been associated with aggressive tumor behavior and recurrence of disease (Ohta et al, 2001a, b; Latif et al, 2004). Simonetti et al. (2009) observed the presence of polysomy 17 in about $60 \%$ (37/63) of the cases with a statistically significant correlation with grade categories $(\mathrm{P}<.0001)$ and tumor stage $(\mathrm{P}=.003)$. Moreover, they interestingly observed polysomy of chromosome 17 in about $30 \%(8 / 29)$ of patients with G2 and these cases showed a poor prognosis, with progression of disease similar to the G3 TCCs.

\section{Conclusions}

FISH had a higher accuracy for detection of HER2 gene in carcinoma of the bladder whether UC or SCC. IHC detection of expression of HER2 protein is less accurate than FISH. In the present study it is recommended to use FISH technique to study the expression of HER2 gene in cases that are planned to receive gene target therapy.

\section{Acknowledgment}

This work was kindly supported by the Internal Research Project $91 / \mathbf{T}$ for Basic and Applied Research, a grant from Theodor Bilharz Research Institute.

\section{Reference}

Abd El-Moneim, HM, Tawfik, HM, ElSherbiny, YM, Twafik, ER, 2011: Analysis of Her2/neu overexpression and amplification in urothelial carcinoma of the bladder associated with cox-2 overexpression. Int. J. Cancer Res.7, $1: 8-2$.

Al-Tereihi, RG, Kerbel, HA, Saheb, RH, AlJanabi, AA, Yasseen, AA, 2011: Over expression of HER-2lneu receptor protein in urinary bladder carcinoma, an immunohistochemical study. Baghdad Fac. Med. 53:2.

Aly, MS, Khaled, HM, 2004: Detection of Cerb B2 gene amplification in bilharzial associated bladder cancer using fluorescence in situ hybridization. Urologic Oncology: Semin. Orig. Investi. 22:448-52.

Felix, AS, Soliman, AS, Khaled, H, Zaghloul, MS, Banerjee, M, El-Baradie, M, et al, 2008: The changing patterns of bladder cancer in Egypt over the past 26 years. Cancer Causes Control 19, 4:421-9.

Atias, GK, Arisan, S, Dalkilinç, A, 2007: Determination of HER2/NEU gene amplification and protein overexpression in bladder transitional cell carcinoma. Adv. Mol. Biol.1:89-94. 
Badr, KM, Nolen, JDL, Msph, PH, 2004: Muscle invasive schistosomal squamous cell carcinoma of the urinary bladder: frequency and prognostic significance of p53, BCL-2, HER2/neu, and proliferation (MIB-1). Hum. Pathol. 35, 2:184-9.

Bartlett, JM, Going, JJ, Mallon, EA, Watters, AD, Reeves, JR, et al, 2001: Evaluating HER2 amplification and over expression in breast cancer. J. Pathol. 195, 4:422-8.

Borden, LS, Clark, PE, Hall, MS, 2004: Bladder cancer. Cuv. Opin. Oncol. 16:257-62.

Charfi, S, Khabir, A, Mnif, H, Ellouze, S, Mhiri, MN, et al, 2013: Immunohistochemical expression of HER2 in urothelial bladder carcinoma and its correlation with P53 and P63 expression. J. Microsc. Ultrastruct.1:17-21.

Droller, MJ, 1998: Bladder cancer, state of the art care. CA Cancer J. Clin. 48:269-84.

Eble, JN, Sauter, G, Epstein, JI, 2004: World Health Organization Classification of tumors: Pathology and Genetics of tumors of the urinary system and male genital organs. IARC Press: Lyon.

El-Baz, HG, Wishahi, MM, Hammam, OA, 2000: Expression of P53 and c- erb-B2 oncoproteins in chronic schistosomal urinary bladder lesions. Kasr El Aini Med. J. 6, 4:503-18.

EL-Bolkainy, MN, Gad EL-Mawala, NG, Khaled, HM, 2000: Bladder cancer in Africa: Update. Semin. Oncol. 920:174-8.

El-Gehani, K, Al-Kikhia, L, Emaetig, F, Syrja, K, Al-Fituri, O, et al, 2012: Overexpression of ER-2 is associated with the stage in carcinomas of the urinary bladder Citation Libyan J Med. 7: 14694.

Eltze, E, Wulfing, C, Von Struensee, D, Piechota, H, et al, 2005: Cox 2 and Her 2 coexpression in invasive bladder cancer. Int. J. Oncol. 26:1525-31.

Gravalos, C, Jimeno, A, 2008: Her2 in gastric cancer, a new prognostic factor and a novel therapeutic target. Ann. Oncol. 10:1093-100.

Griffiths, G, Hall, R, Sylvester, R, Raghavan, -D, Parmar, MK, 2011: International phase III trial assessing neoadjuvant cisplatin, methotrexate, and vinblastine chemotherapy for muscleinvasive bladder cancer: long-term results of the BA06 30894 trial. J. Clin. Oncol. 29, 16:2171-7. Hansel, DE, Swain, E, Dreicer, R,Tubbs, RR, 2008: HER2 overexpression and amplification in urothelial carcinoma of the bladder is associ- ated with MYC coamplification in a subset of cases. Am. J. Clin. Pathol. 130:274-81.

Hsu, SM, Raine, L, Fauger, H, 1981: Use of avidin-biotin peroxidase complex (ABC) in immunoperoxidase technique: a comparison between $\mathrm{ABC}$ and unlabelled antibody (PAP) procedure. J. Histochem. 29:577-80.

IARC Working Group on the Evaluation of Carcinogenic Risks to Humans 1994: Schistosomes, liver flukes and Helicobacter pylori. Lyon, 7-14 June 1994. IARC Monogr. Eval. Carcinog Risks Hum. 61:1-241.

Jung, I, Messing, E, 2002: Molecular mechanisms and pathways in bladder cancer development and progression. Cancer Control 7: 325-34.

Kaptain, S, Tan, LK, Chen, B, 2001: Her2 and breast cancer. Diag. Mol. Path. 10:139-152

Khan, MA, Travis, LB, Lynch, CF, et al, 1998: P53 mutations in cyclophosphamide associated bladder cancer. Cancer Epidemiol. Biomark. Prev. 7:397-403.

Koraitim, MM, Metwalli, NE, Atta, MA, ElSadr, AA, 1995: Changing age incidence and pathological types of schistosoma-associated bladder carcinoma. J. Urol. 154, 5:1714-6.

Korkolopoulou, P, Christodoulou, P, Kapralos, P, Exarchakos M, Bisbiroula, A, et al, 1997: The role of p53, MDM2 and c-erb B-2 oncoproteins, epidermal growth factor receptor and proliferation markers in the prognosis of urinary bladder cancer. Pathol. Res. Pract. 193:767-75

Krüger, S, Weitsch, G, Bütiner, H, et al, 2002: HER2 overexpression in muscle-invasive urothelial carcinoma of the bladder: prognostic implications. Int. J. Cancer 102:514-8.

Latif, Z, Watters, AD, Dunn, I, Grigor, K, Underwood, MA, et al, 2004: HER2/neu gene amplification and protein overexpression in G3 pT2 transitional cell carcinoma of the bladder: a role for anti-HER2/neu therapy? Eur. J. Cancer 40:56-63.

Latif Z, Watters, AD, Dunn, I, Grigor, KM, Underwood, MA, Bartlett, JM, 2003: HER2/ neu overexpression in the development of muscle-invasive transitional cell carcinoma of the bladder. Br J Cancer, 89: 1305-1309.

Mostafa, MH, Sheweita, SA, O'Connor, PJ, 1999: Relationship between schistosomiasis and bladder cancer. Clin. Microbiol. Rev.12:97-111. Nadoushan, MR, Taheri, T, Jouian, N, Zaeri, F, 2007: Overexpression of HER-2/neu onco- 
gene and transitional cell carcinoma of bladder. Urol. J. 4:151-154.

Nakopoulou, L, Vourlakou, C, Zervas A, 1998: The prevalence of bcl-2, p53, and Ki-67 immunoreactivity in transitional cell bladder carcinomas and their clinicopathologic correlates. Hum. Pathol. 29:146-54.

Ohta, JI, Miyoshi, Y, Uemura, H, et al, 2001a: Fluorescence in situ hybridization evaluation of c-erbB-2 gene amplification and chromosomal anomalies in bladder cancer. Clin. Cancer Res. 7:2463-7.

Ohta, JI, Miyoshi, Y, Uemura, H, Fujinami, K, Mikata, K, et al, 2001b: Fluorescence in situ hybridization evaluation of c-erbB-2 gene amplification and chromosomal anomalies in bladder cancer. Clin. Cancer Res. 7: 2463-7.

Parkin, DM, Bray, F, Ferlay, J, Pisani, P, 2005: Global cancer statistics, 2002. CA: A Cancer J. Clin. 55, 2:74-108.

Ramzi, C, Vinay, K, Stanley, LR, 2000: Urinary bladder. In: Ramzi C, Vinay K, Stanley C, editors: Robbins Pathologic Basis of Disease. Philadelphia: WB Saunders.

Sato, K, Moriyama, M, Mori, S, Saito, M, Watanuki, T, et al, 1992: An immunohistologic evaluation of cerbB 2-gene product in patients with urinary bladder carcinoma. Cancer 15:2493-8.

Schuell, B, Gruenbergger, T, Scheithauer, W, et al, 2006: Her2 protein expression in colorectal cancer. BMC Cancer 8:123-9.

Simonetti, S, Russo, R, Ciancia, G, Altieri, V, De Rosa, G, et al, 2009: Role of Polysomy 17 in Transitional Cell Carcinoma of the Bladder: Immunohistochemical Study of HER2/neu Expression and FISH Analysis of c-erbB-2 Gene and Chromosome 17. Int. J. Surg. Pathol.17: 198.

Smith, I, Procter, M, Gelber, RD, Guillaume, S, Feyereislova, A, et al, 2007: Two-year follow-up of trastuzumab after adjuvant chemotherapy in HER2-positive breast cancer: a randomized controlled trial. Lancet, 369, 9555:2936.

Trkova, M, Babjuk, M, Duskova, J, et al, 2006: Analysis of genetic events in $17 \mathrm{p} 13$ and 9p21 regions supports predominant monoclonal origin of multifocal and recurrent bladder cancer. Cancer Lett, 242: 68-76.

Tryls, G, Kennet, W, Manuel, De La, T, 2005: Analysis of Her-2 Ineu expression in primary urinary bladder carcinoma and corresponding metastases. J. Pathol. 95:982-6.

Underwood, M, Bartlett, J, Reeves, J, et al, 1995: C-erbB-2 gene amplification: A molecular marker in recurrent bladder tumors? Cancer Res. 55:2422-30.

Wester, K, Sjo, M, de la Torre, M, Carlsson, J, Malmstro“m, P, 2002: HER-2-A possible target for therapy of metastatic urinary bladder carcinoma. Acta Oncol. 3:282-8.

Wülfing, C, Von Struensee, D, Bierer, S, ögemann, M, Hertle, L, et al, 2005: Expression of Her2/neu in locally advanced bladder cancer: implication for a molecular targeted therapy. Aktuelle Urol. 36: 823-923. 

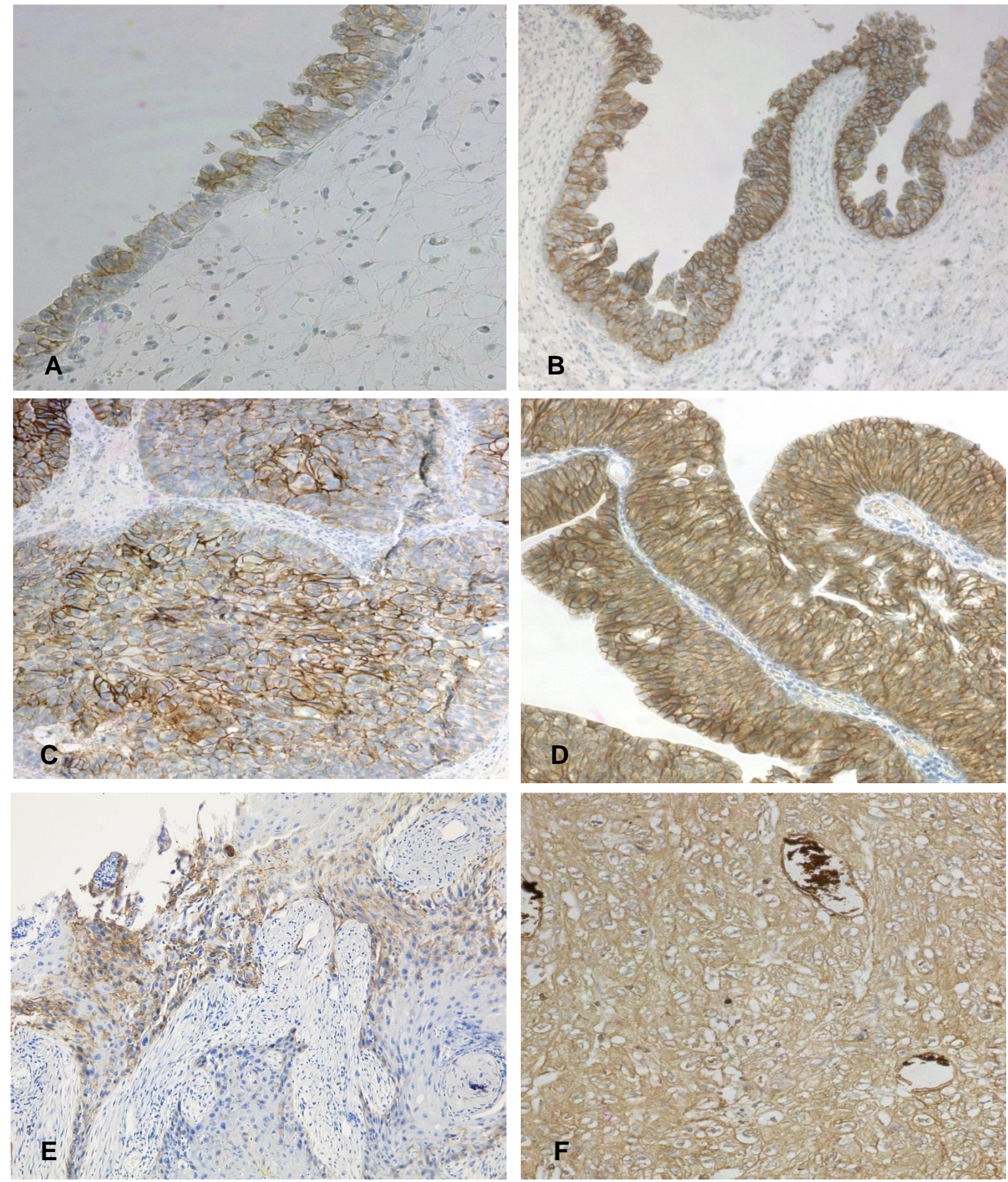

Fig. 1 A-F: A) A control case showing negative HER2 protein, score 1+ in the urothelial lining, B) A case of polypod cystitis showing negative HER2 protein immunoexpression, score 2+, (IHC, HER2, DAB, x200), C) A case of poorly differentiated urothelial (Transitional) cell carcinoma. Showing equivocal HER2 protein immunoexpression HER2 in more than $30 \%$ of tumor cells, (IHC, HER2, DAB, x400), D) A case of papillary urothelial carcinoma showing strong HER2 protein immunoexpression, score $3+$ in more than $70 \%$ of cases, (IHC, HER2, DAB, x400), E) A case of moderately differentiated Bilharzial associated squamous cell carcinoma, strongly positive for HER2 protein ore 3+, (IHC, HER2, DAB, x400), F) A case of moderately differentiated squamous cell carcinoma, grade II showing negative HER2 protein immunoexpression, score 1+, (IHC, HER2, DAB, x200). 


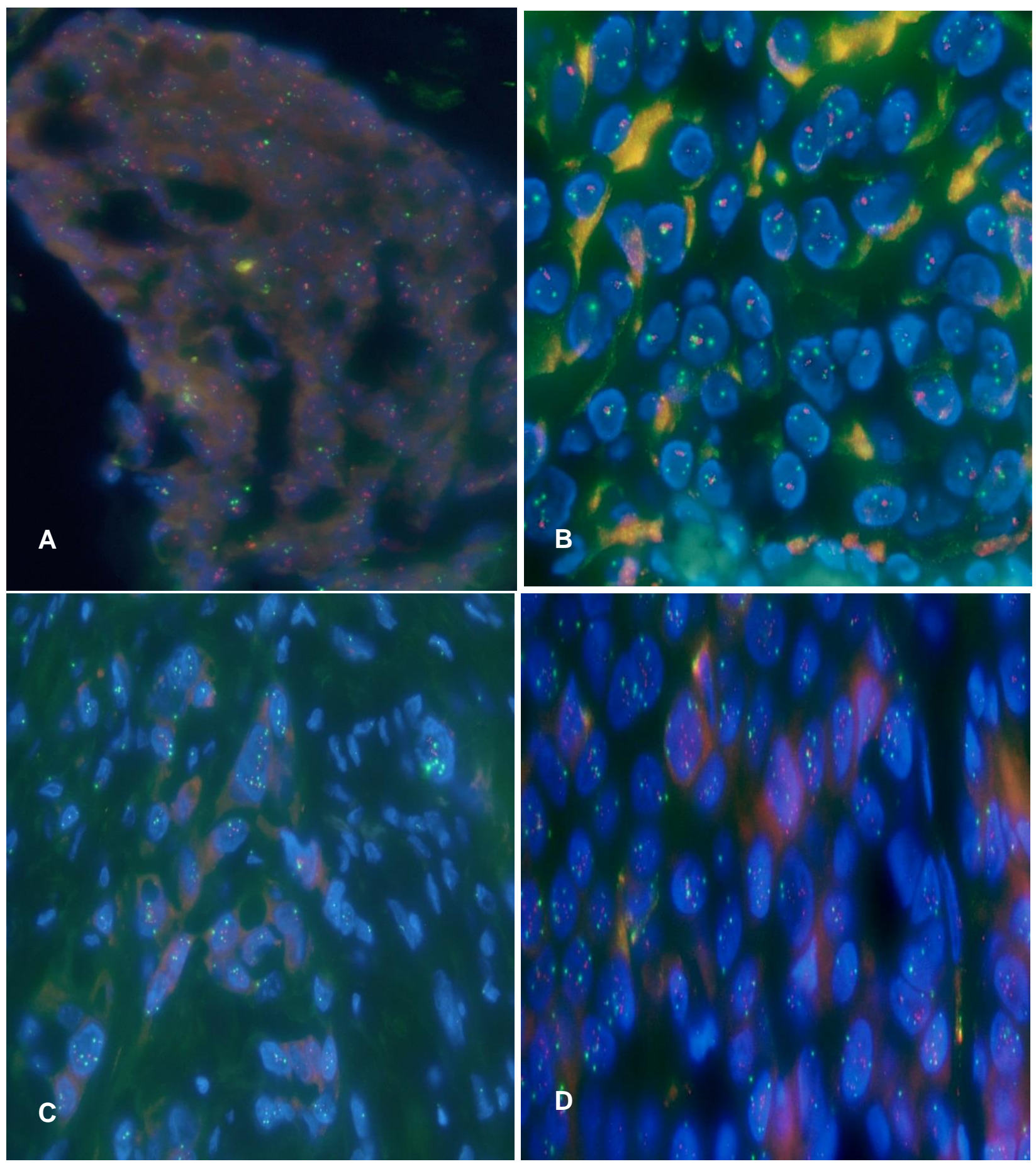

Fig. 2; A-D: A) A case of papillary urothelial (Transitional) cell carcinoma, positive for HER2 gene amplification, showing red clusters, B) A case of urothelial (Transitional) cell carcinoma, positive for HER2 gene amplification, showing red clusters, C) A case of squamous cell carcinoma, negative for HER2 gene amplification, D) A case of squamous cell carcinoma, positive for HER2 gene amplification, showing more than 6 red signals per cell, (FISH, HER2 gene, x1000). 


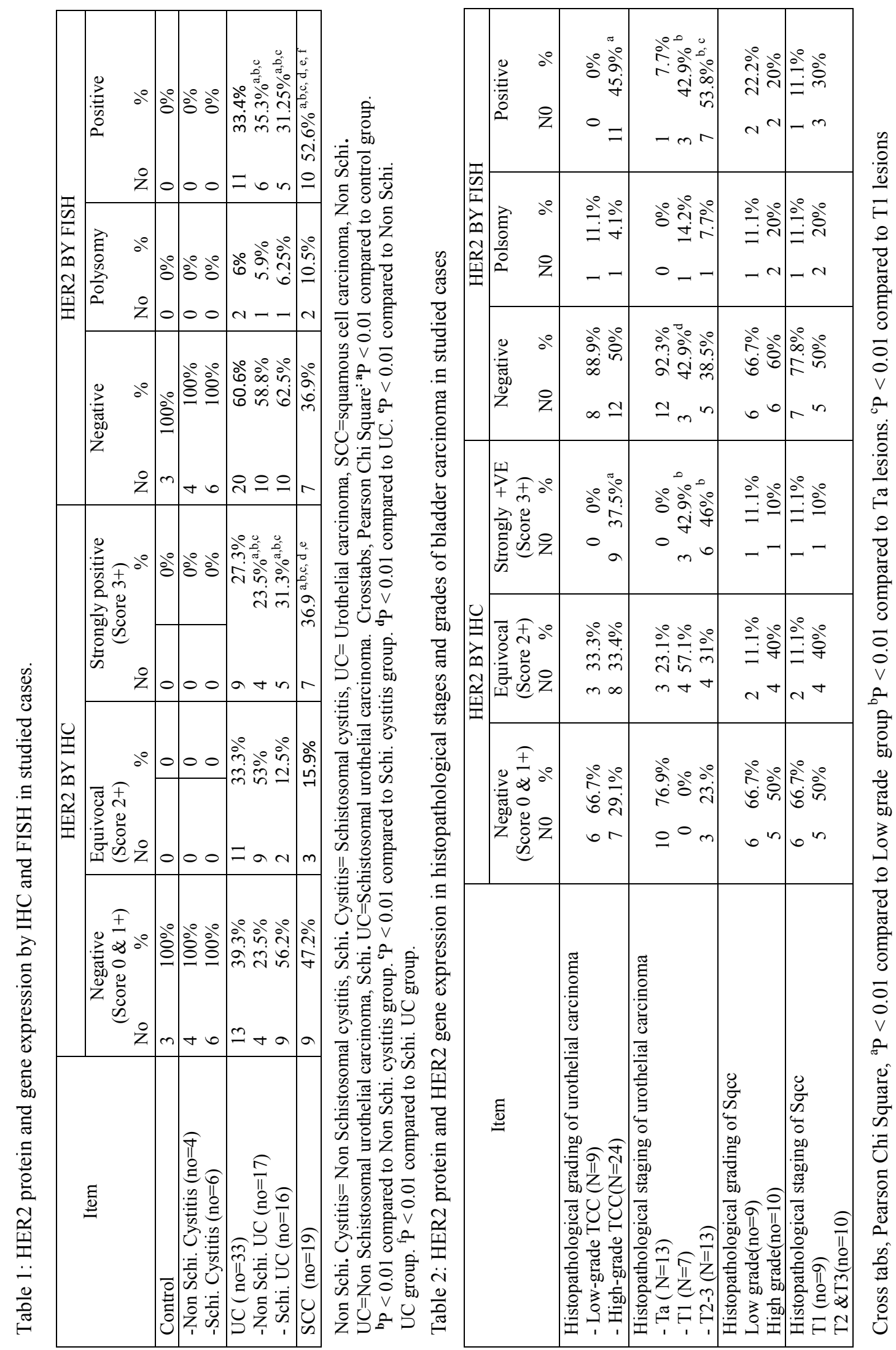

$\bar{n}$ 